\title{
GRAPH OF FINITE SEQUENCE OF FUZZY TOPOGRAPHIC TOPOLOGICAL MAPPING OF ORDER TWO
}

\author{
${ }^{1,2}$ Mohamed Sayed and ${ }^{1,3}$ Tahir Ahmad \\ ${ }^{1}$ Department of Mathematical Science, \\ University Teknologi Malaysia, 81310 Skudai, Johor, Malaysia \\ ${ }^{2}$ Department of Mathematical Science, International University of Africa, Sudan \\ ${ }^{3}$ Ibnu Sina Institute for Fundamental Science Studies \\ University Teknologi Malaysia, 81310 Skudai, Johor, Malaysia
}

Received 2011-09-13, Revised 2013-02-28; Accepted 2013-03-15

\begin{abstract}
Fuzzy Topographic Topological Mapping (FTTM) was built to solve the neuromagnetic inverse problem to determine the location of epileptic foci in epilepsy disorder patient. The model which consists of topological and fuzzy structures is composed into three mathematical algorithms. FTTM consists of four topological spaces and connected by three homeomorphisms. FTTM version 1 is also homeomorphic to FTTM version 2. This homeomorphism generates another 14 elements of FTTM. In this study we proved that, if there exist n elements of FTTM, the new elements of order 2 will produce a graph of degree $24 n^{2}-16 n-8$. In this study, the statement is proven by viewing FTTMs as sequence and using its graphical features. In the process, several definitions and theorems were developed.
\end{abstract}

Keywords: Fuzzy Topographic Topological Mapping, Sequence of FTTM ${ }_{n}$, Element of Order Two, M $_{1}$

\section{INTRODUCTION}

FTTM version 1 consists of three algorithms, which link between four components. The four components are magnetic contour plane $\left(M_{1}\right)$, base magnetic plane $\left(B_{1}\right)$, fuzzy magnetic field $\left(\mathrm{F}_{1}\right)$ and topographic magnetic field $\left(\mathrm{T}_{1}\right)$, as shown in Fig. 1.

FTTM version 1 was developed to present a 3-D view of unbounded signal current source (Fauziah, 2002; Liau, 2001).

Besides that, FTTM version 2 can processed image data of magnetic field.

FTTM version 1 as well as FTTM version 2 are specially designed to have equivalent topological structures between its components (Yun, 2006). In other words, there are homeomorphisms between each element of FTTM version 1 and FTTM version 2 (Yun, 2006) (Fig. 2).

Yun (2006) first noticed that if there were two elements of FTTM that are homeomorphic to each other component wise, it would generate more homeomorphisms. The numbers of generating new elements of FTTM are:

$$
\left[\left(\begin{array}{l}
2 \\
1
\end{array}\right) \times\left(\begin{array}{l}
2 \\
1
\end{array}\right) \times\left(\begin{array}{l}
2 \\
1
\end{array}\right) \times\left(\begin{array}{l}
2 \\
1
\end{array}\right)\right]-2=14 \text { elements }
$$

Consequently, Yun (2006) proposed a conjecture such that, if there exist n elements of FTTM, then the number of new elements are $n^{4}-n$.

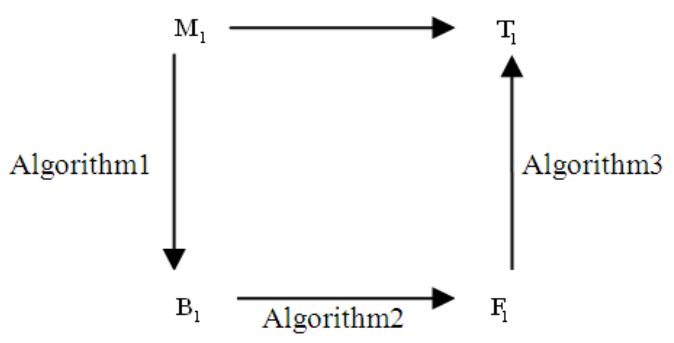

Fig. 1. FTTM Version 1 Corresponding Author: Mohamed Sayed, Department of Mathematical Science, University Teknologi Malaysia, 81310 Skudai, Johor, Malaysia 


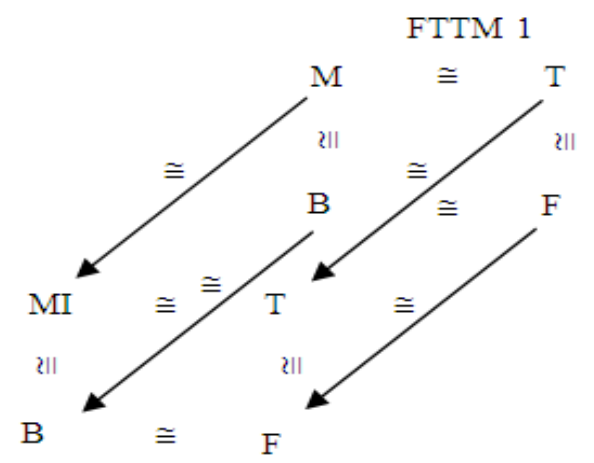

FTTM 2

Fig. 2. Homeomorphisim Between FTTM 1 and FTTM 2

The above conjecture finally proved by (Ahmed et al., 2010) as stated below.

\section{Theorem 1}

If there exist $n$ elements of FTTM, the numbers of new elements are $n^{4}-n$.

\section{MATERIALS AND METHODS}

\section{Definition 1: (Ahmed et al., 2010)}

Let

$$
\text { FTTM }_{\mathrm{i}}=\left(\mathrm{M}_{\mathrm{i}}, \mathrm{B}_{\mathrm{i}}, \mathrm{F}_{\mathrm{i}}, \mathrm{T}_{\mathrm{i}}\right) \text { such }
$$

that $\mathrm{M}_{\mathrm{i}}, \mathrm{B}_{\mathrm{i}}, \mathrm{F}_{\mathrm{i}}$ and $\mathrm{T}_{\mathrm{i}}$ are topological

spaces with $\mathrm{M}_{\mathrm{i}} @ \mathrm{~B}_{\mathrm{i}} @ \mathrm{~F}_{\mathrm{i}} @ \mathrm{~T}_{\mathrm{i}}$. Sequence of n FTTM $\mathrm{F}_{\mathrm{i}}$ of FTTM is FTTM $_{1}, \mathrm{FTTM}_{2}, \mathrm{FTTM}_{3}, \ldots, \mathrm{FTTM}_{\mathrm{n}}$, such that $M_{i} @ M_{i+1}, B_{i} @ B_{i+1}, F_{i} @ F_{i+1}, T_{i} @ T_{i+1}$ (Fig.3).

In this study we present a new notion of sequence of FTTM namely "Order of the new elements" and this study will deal with graph of the new elements of order two.

In the following definition cube order of FTTM is presented.

\section{Definition 2}

The cube that produced from a combination of FTTM $_{\mathrm{i}}$ in $\mathrm{FTTM}_{n}$ is said to be a cube of order $\mathrm{i}$ and $\mathrm{i}=2,3,4$.

It is impossible to develop cubes from the combination of five or more terms FTTM.

\section{Notation}

- $\mathrm{C}_{\mathrm{i}, \mathrm{j}}$ FTTM $_{\mathrm{i}}$ presents the cubes of order two that can be produced from the combination of $\mathrm{FTTM}_{\mathrm{i}}$ in FTTM $_{\mathrm{n}}$ in $\mathrm{FTTM}_{\mathrm{n}}$, where $1 \leq \mathrm{i}<\mathrm{j} \leq \mathrm{n}$ :

- $\mathrm{I}=\{1,2,3,4, \ldots, \mathrm{n}-1\}$

- $\mathrm{J}=\{2,3,4, \ldots, \mathrm{n}\}$

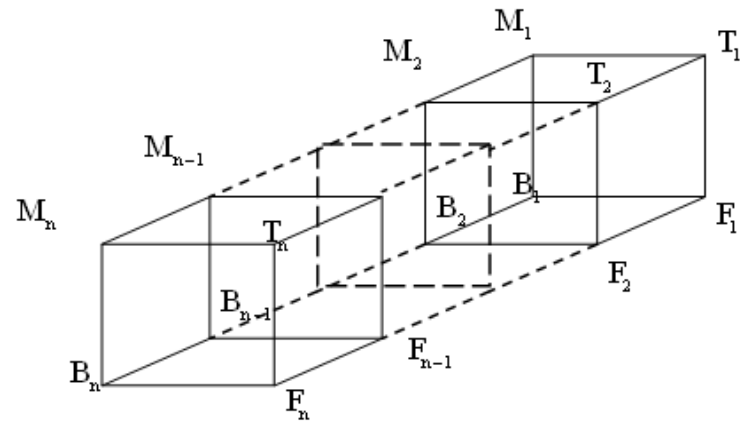

Fig. 3. Sequence of FTTM

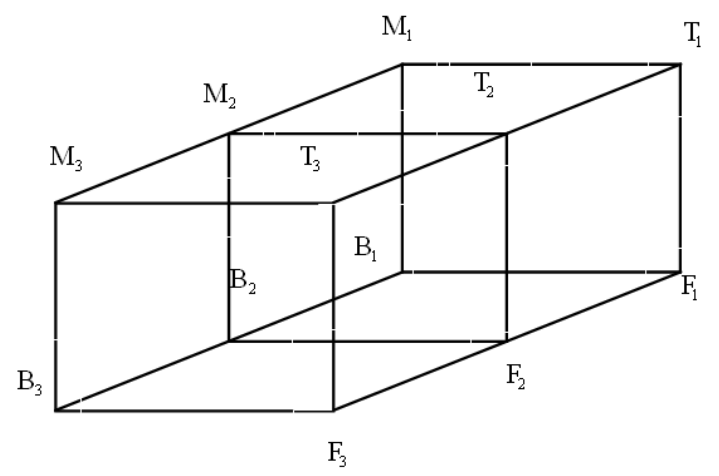

Fig. 4. $\mathrm{FTTM}_{3}$

- $\quad\left|\mathrm{C}_{\mathrm{i}, \mathrm{j}} \mathrm{FTTM}_{\mathrm{n}}\right|_{\mathrm{i} \in \mathrm{I}, \mathrm{j} \in \mathrm{J}, \mathrm{i}<j \leq \mathrm{n}}$ presents, the number of cubes of order two that can be produced from the combination

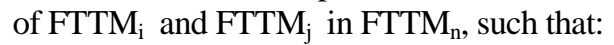

$$
\mathrm{i} \in \mathrm{I}, \mathrm{j} \in \mathrm{J}, \quad \forall \mathrm{i}<\mathrm{j} \leq \mathrm{n}
$$

\section{Example 1}

In $\mathrm{FTTM}_{3}$ From Fig. 4 we can find that:

$$
\begin{gathered}
\mathrm{C}_{\mathrm{i}, \mathrm{j}} \mathrm{FTTM}_{3}=\mathrm{C}_{1,2} \text { FTTM }_{3}, \mathrm{C}_{2,3} \text { FTTM }_{3}, \\
\mathrm{C}_{1,3} \text { FTTM }_{3} \\
\mid \mathrm{C}_{\mathrm{i}, \mathrm{j}} \text { FTTM }\left._{3}\right|_{\mathrm{i} \in \mathrm{I}, \mathrm{j} \in \mathrm{J}, \mathrm{i}<\mathrm{j} \leq 3}=3
\end{gathered}
$$

Now we have the following lemma.

\section{Lemma 1}

$$
\begin{aligned}
\left|\mathrm{C}_{\mathrm{i}, \mathrm{j}} \operatorname{FTTM}_{\mathrm{n}}\right|_{\mathrm{i} \in \mathrm{I}, \mathrm{j} \in \mathrm{J}, \mathrm{i}<j \leq \mathrm{n}} & =1+2+3+\ldots \\
& +(\mathrm{n}-2)+(\mathrm{n}-1) \\
& =\frac{\mathrm{n}(\mathrm{n}-1)}{2}
\end{aligned}
$$




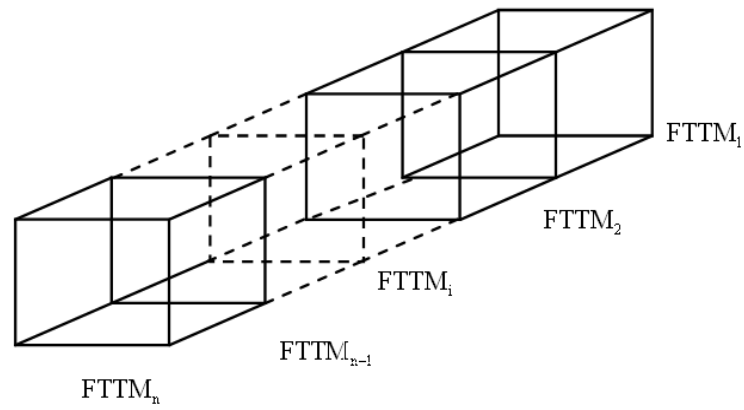

Fig. 5. Sequence of FTTM $_{n}$

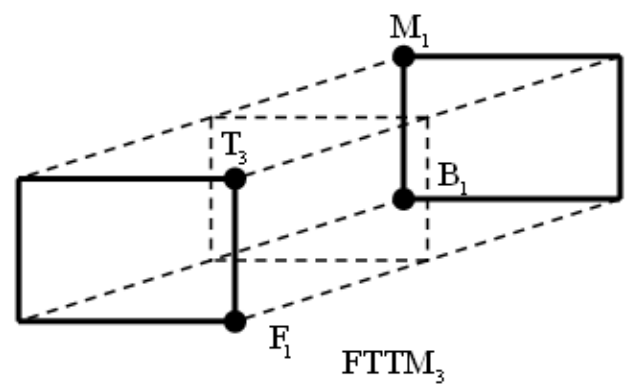

Fig. 6. $\left(M_{1}, B_{1}, F_{3}, T_{3}\right)$

\section{Proof}

From Fig. 5:

$$
\begin{aligned}
& S_{1}=\left|C_{i, i+1} \operatorname{FTTM}_{n}\right|_{i \in I, j \in J, i<j \leq n}=n-1 \\
& S_{2}=\left|C_{i, i+2} \operatorname{FTTM}_{n}\right|_{i \in I, j \in J, i<j \leq n}=n-2 \\
& \vdots \\
& S_{n-2}=\left|C_{i, n-2} \operatorname{FTTM}_{n}\right|_{i \in I, j \in J, i<j \leq n}=3 \\
& S_{n-1}=\left|C_{i, n-1} \operatorname{FTTM}_{n}\right|_{i \in I, j \in J, i<j \leq n}=2 \\
& S_{n}=\left|C_{i, n} \operatorname{FTTM}_{n}\right|_{i \in I, j \in J, i<j \leq n}=1
\end{aligned}
$$

FTTM $_{1}$

Now let:

$$
\mathrm{S}=\sum_{\mathrm{i}=1}^{\mathrm{n}} \mathrm{S}_{\mathrm{i}}
$$

Therefore:

$$
\begin{aligned}
2 \mathrm{~S}= & 1+2+3+\cdots \\
& +(\mathrm{n}-2)+(\mathrm{n}-1) \\
& +(\mathrm{n}-1)+(\mathrm{n}-2) \\
& +\cdots+2+1
\end{aligned}
$$

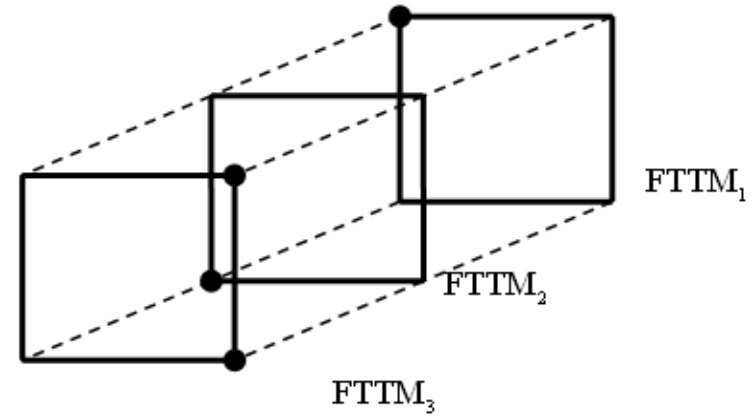

Fig. 7. $\left(M_{1}, B_{1}, F_{3}, T_{3}\right)$

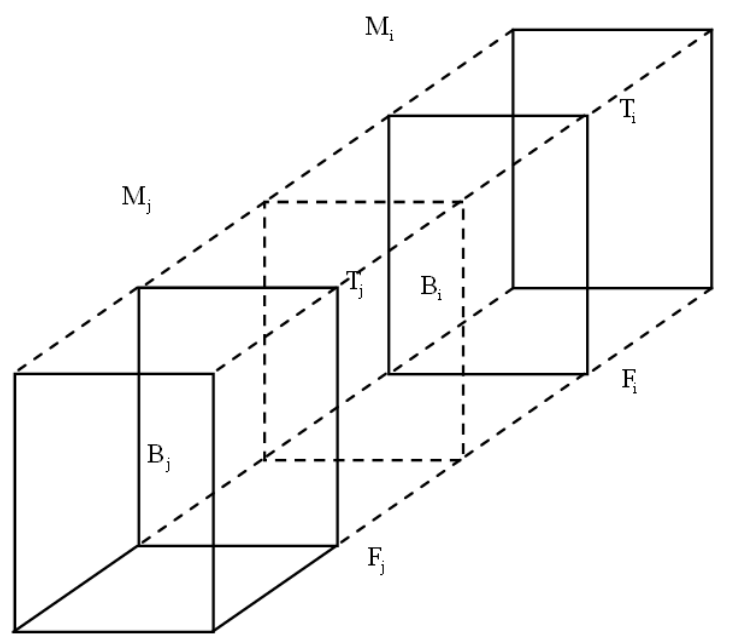

Fig. 8. FTTM $_{\mathrm{i}}$ and $\mathrm{FTTM}_{\mathrm{j}}$

$$
\begin{aligned}
& =n(n-1) \\
& S=\frac{n(n-1)}{2}
\end{aligned}
$$

Here we introduce a new definition.

\section{Definition 3}

The new element is said to be an element of order I if its components appear in exactly $i$ versions of FTTM $_{n}$. $\mathrm{i}=2,3,4$.

\section{Example 2}

$\left(\mathrm{M}_{1}, \mathrm{~B}_{1}, \mathrm{~F}_{3}, \mathrm{~T}_{3}\right)$ is an element of order two, since its components appear in FTTM $_{1}$ and FTTM $_{3}$ (Fig. 6).

By replacing $B_{1}$ with $B_{2}$, then $\left(M_{1}, B_{1}, F_{3}, T_{3}\right)$ is an element of order three, since its components appear in

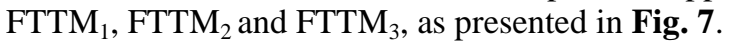

The following lemma is immediate. 


\section{Lemma 2}

Any $\mathrm{C}_{\mathrm{i}, \mathrm{j}} \mathrm{FTTM}_{\mathrm{n}}$ will generate 14 new elements of order two.

\section{Proof}

Without loss of generality, consider FTTM $_{1}$ and FTTM $_{j}$ where $(i \in I, j \in J, i<j \leq n)$ as in Fig. 8.

The new elements can be generated by simple construction, as given below:

$$
\begin{aligned}
& \left(M_{i}, B_{i}, F_{i}, T_{j}\right),\left(M_{i}, B_{i}, F_{j}, T_{i}\right) \\
& \left(M_{i}, B_{j}, F_{i}, T_{i}\right),\left(M_{j}, B_{i}, F_{i}, T_{i}\right) \\
& \left(M_{i}, B_{i}, F_{j}, T_{j}\right),\left(M_{i}, B_{j}, F_{i}, T_{j}\right) \\
& \left(M_{j}, B_{i}, F_{i}, T_{j}\right),\left(M_{i}, B_{j}, F_{j}, T_{i}\right) \\
& \left(M_{j}, B_{i}, F_{j}, T_{i}\right),\left(M_{j}, B_{j}, F_{i}, T_{i}\right) \\
& \left(M_{i}, B_{j}, F_{j}, T_{j}\right),\left(M_{j}, B_{j}, F_{i}, T_{j}\right) \\
& \left(M_{j}, B_{j}, F_{j}, T_{i}\right),\left(M_{j}, B_{i}, F_{j}, T_{j}\right)
\end{aligned}
$$

All the above elements are of order two.

\section{Notation}

Some new notations are introduced as follows:

- $\alpha_{a}$ FTTM $_{n}$ presents the set of all elements of order $\alpha$ that can be generated by FTTM $_{n}$

- $\quad \beta_{a}$ FTTM $_{n}$ presents the set of all elements of order other than $\alpha$, that can be generated by $\operatorname{FTTM}_{n}$ below.

Consequently, the following theorem is presented as

\section{Theorem 2}

$$
\begin{aligned}
& \left|\alpha_{2} \operatorname{FTTM}_{n}\right|=7\left(n^{2}-n\right) \text { and } \\
& \left|\beta_{2} \operatorname{FTTM}_{n}\right|=n^{4}-7 n^{2}+6 n
\end{aligned}
$$

\section{Proof}

From Definition 2, Lemma 1 and Lemma 2:

$$
\begin{aligned}
& \left|\alpha_{2} \operatorname{FTTM}_{n}\right|=14 \times\left|C_{i, j} \operatorname{FTTM}_{n}\right|_{i \in I, j \in J, i<j \leq n} \\
& =14 \times \frac{n(n-1)}{2} \\
& =7 n(n-1) \\
& =7\left(n^{2}-n\right)
\end{aligned}
$$

Table 1. Elements of Order Two

\begin{tabular}{lccr}
\hline $\mathrm{N}$ & $\left|\alpha_{2} \mathrm{FTTM}_{\mathrm{n}}\right|$ & $\left|\beta_{2} \mathrm{FTTM}_{\mathrm{n}}\right|$ & $\mathrm{n}{ }^{4}-\mathrm{n}$ \\
\hline 1 & 0 & 0 & 0 \\
2 & 14 & 0 & 14 \\
3 & 42 & 36 & 87 \\
4 & 84 & 168 & 252 \\
5 & 140 & 480 & 620 \\
6 & 210 & 1080 & 1290 \\
7 & 294 & 2100 & 2394 \\
8 & 392 & 3696 & 4088 \\
9 & 504 & 6048 & 6552 \\
10 & 630 & 9360 & 999 \\
\hline
\end{tabular}

Now by subtracting the number of the new elements of order two from the total number of new elements then the number of new elements of order other than two (three and four ) can be deduced as follows:

$$
\begin{aligned}
& \left|\beta_{2} \operatorname{FTTM}_{n}\right|=n^{4}-n-7\left(n^{2}-n\right) \\
& =n^{4}-n-7 n^{2}+7 n \\
& =n^{4}-7 n^{2}+6 n
\end{aligned}
$$

\subsection{Computational Results}

In the previous discussion we show that the number of the new elements of order two equal to $7\left(n^{2}-n\right)$ and the number of the new elements of order other than two equal to $n^{4}-7 n^{2}+6 n$.

The number of the new elements of order two and of order other than two, for $n=1,2,3, \ldots, 10$ is given in the following Table 1.

\section{Lemma 3}

Any element of order two will produce a graph of degree 4 or zero.

\section{Proof}

Since the element is of order two, its graph will appear in exactly two versions of FTTM in FTTM . $_{\text {. }}$ From Lemma 2, FTTM $\mathrm{i}$ and $\mathrm{FTTM}_{\mathrm{j}}$ will generate 14 new elements of order two and of 12 of them will produce a graph of degree 4, namely:

$$
\begin{aligned}
& \left(M_{i}, B_{i}, F_{i}, T_{j}\right),\left(M_{i}, B_{i}, F_{j}, T_{i}\right) \\
& \left(M_{i}, B_{j}, F_{i}, T_{i}\right),\left(M_{j}, B_{i}, F_{i}, T_{i}\right) \\
& \left(M_{i}, B_{i}, F_{j}, T_{j}\right),\left(M_{j}, B_{i}, F_{i}, T_{j}\right) \\
& \left(M_{i}, B_{j}, F_{j}, T_{i}\right),\left(M_{j}, B_{j}, F_{i}, T_{i}\right) \\
& \left(M_{i}, B_{j}, F_{j}, T_{j}\right),\left(M_{j}, B_{j}, F_{i}, T_{j}\right) \\
& \left(M_{j}, B_{j}, F_{j}, T_{i}\right),\left(M_{j}, B_{i}, F_{j}, T_{j}\right)
\end{aligned}
$$




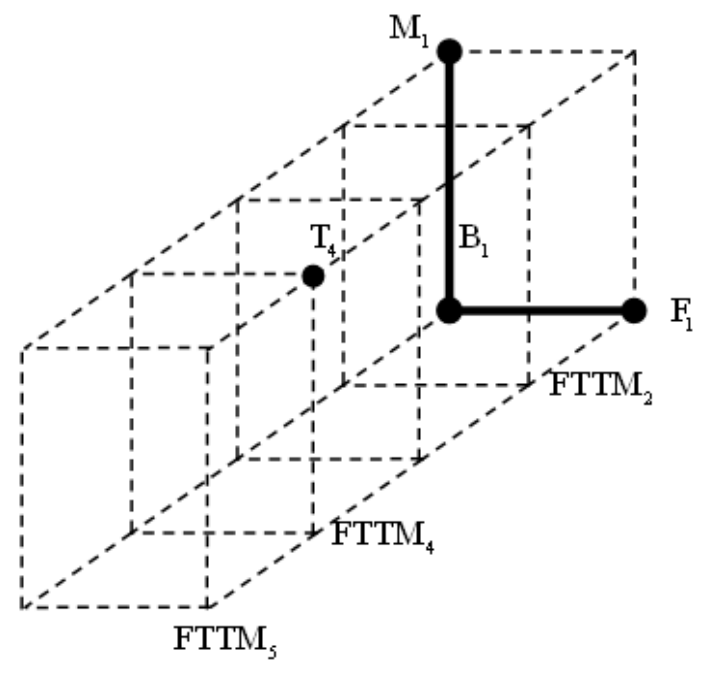

Fig. 9. $\left(M_{1}, B_{1}, F_{1}, T_{4}\right)$

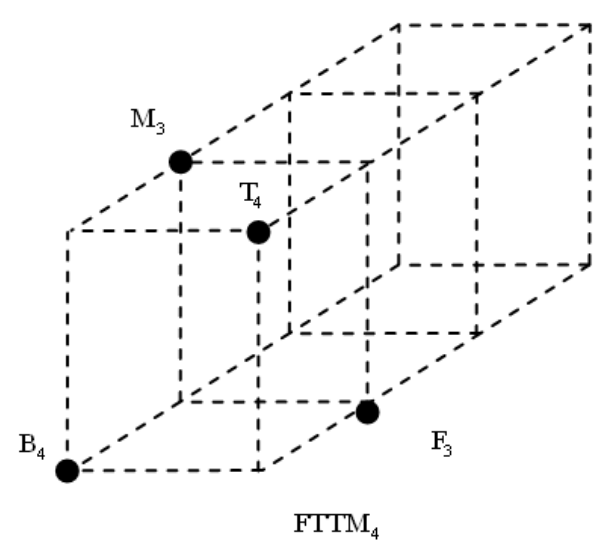

Fig. 10. $\left(M_{1}, B_{1}, F_{1}, T_{4}\right)$

And 2 elements will produce a graph of degree zero, $\left(\mathrm{M}_{\mathrm{i}}, \mathrm{B}_{\mathrm{j}}, \mathrm{F}_{\mathrm{i}}, \mathrm{T}_{\mathrm{j}}\right)$ and $\left(\mathrm{M}_{\mathrm{j}}, \mathrm{B}_{\mathrm{i}}, \mathrm{F}_{\mathrm{j}}, \mathrm{T}_{\mathrm{i}}\right)$ since all its vertices are isolated (No homeomorphism between its components).

\section{Example 3}

Any element of order two of the form $\left(\mathrm{M}_{\mathrm{i}}, \mathrm{B}_{\mathrm{j}}, \mathrm{F}_{\mathrm{i}}, \mathrm{T}_{\mathrm{j}}\right)$ will produce a graph of degree four, $\forall \mathrm{i}<\mathrm{j} \leq \mathrm{n}$.

To see this let $\mathrm{i}=2, \mathrm{j}=4, \mathrm{n}=5$, (Fig. 9).

The degree of the graph:

$$
\begin{aligned}
& =\operatorname{deg}\left(\mathrm{v}_{1}\right)+\operatorname{deg}\left(\mathrm{v}_{2}\right)+\operatorname{deg}\left(\mathrm{v}_{3}\right)+\operatorname{deg}\left(\mathrm{v}_{4}\right) \\
& =\operatorname{deg}\left(\mathrm{M}_{1}\right)+\operatorname{deg}\left(\mathrm{B}_{1}\right)+\operatorname{deg}\left(\mathrm{F}_{1}\right)+\operatorname{deg}\left(\mathrm{T}_{4}\right) \\
& =1+2+1+0 \\
& =4
\end{aligned}
$$

\section{Example 4}

Any element of order two of the form $\left(\mathrm{M}_{\mathrm{i}}, \mathrm{B}_{\mathrm{j}}, \mathrm{F}_{\mathrm{i}}, \mathrm{T}_{\mathrm{j}}\right)$ will produce a graph of degree zero, $\forall \mathrm{i}<\mathrm{j} \leq \mathrm{n}$.

To see this let $\mathrm{i}=3, \mathrm{j}=4, \mathrm{n}=4$, (Fig. 10).

The degree of the graph:

$$
\begin{aligned}
& =\operatorname{deg}\left(\mathrm{v}_{1}\right)+\operatorname{deg}\left(\mathrm{v}_{2}\right)+\operatorname{deg}\left(\mathrm{v}_{3}\right)+\operatorname{deg}\left(\mathrm{v}_{4}\right) \\
& =\operatorname{deg}\left(\mathrm{M}_{3}\right)+\operatorname{deg}\left(\mathrm{B}_{4}\right)+\operatorname{deg}\left(\mathrm{F}_{3}\right)+\operatorname{deg}\left(\mathrm{T}_{4}\right) \\
& =0+0+0+0 \\
& =0
\end{aligned}
$$

\section{RESULTS AND DISCUSSION}

Finally, the new result follows.

\section{Theorem 3}

The new elements of order two will construct a graph of degree $24 n^{2}-16 n-8$.

\section{Proof}

From Theorem 2, Lemma 1, Lemma 2 and Lemma 3 Equation 1:

$\operatorname{Deg}\left(\alpha_{2} \operatorname{FTTM}_{n}\right)=\frac{n(n-1)}{2} \times(12) \times(4)+H$
$=24\left(n^{2}-n\right)+H$

Such that $\mathrm{H}$ is the number of added edges to the graph, since FTTM $_{i}$ and FTTM $_{i+1}$ are homeomorphic component wise, therefore Equation 2:

$$
\begin{aligned}
& H=2(4)+8(n-2) \\
& =8+8 n-16 \\
& =8 n-8
\end{aligned}
$$

\section{Substitute (2) into (1):}

$$
\begin{aligned}
& \operatorname{Deg}\left(\alpha_{2} \operatorname{FTTM}_{n}\right)=24\left(n^{2}-n\right)+8 n-8 \\
& =24 n^{2}-16 n-8
\end{aligned}
$$

\section{CONCLUSION}

In this study, it is proven that if there exist $\mathrm{N}$ elements of FTTM of order two, then it will produce a graph of degree $24 n^{2}-16 n-8$. 


\section{REFERENCES}

Ahmed, T., S.S. Jamian and J. Talib, 2010. Generalized finite sequence of fuzzy topographic topological mapping. Math. Stat., 6: 151-156. DOI: 10.3844/jmssp.2010.151.156

Fauziah, Z., 2002. Algorithma Penyelesan Masala Songsang Arus Tunggal Tak Terbatas MEG. University Teknologi Malaysia, Tesis Sarjana.
Liau, L.Y., 2001. Homeomorfisma S2 Antara E2 Melalui Struktur Permukaan Riemann serta Deduksi Teknik pembuktiannya bagi Homeomorfisma pemetaan Topologi Topografi Kabur (FTTM). University Teknologi Malaysia, Tesis Sarjana.

Yun, L.L., 2006. Group-like algebraic structures of fuzzy topographic topological mapping for solving neuromagnetic inverse problem. Ph.D. Thesis, University Technology Malaysia. 